Please do not remove this page

RMIT

UNIVERSITY

\title{
An analysis tool for design and certification of postbuckling composite aerospace structures
}

Orifici, Adrian; Thomson, Rodney; Degenhardt, Richard; Bisagni, Chiara; Bayandor, Javid https://researchrepository.rmit.edu.au/esploro/outputs/9921857958201341/filesAndLinks?institution=61RMIT_INST\&index=null

Orifici, A., Thomson, R., Degenhardt, R., Bisagni, C., \& Bayandor, J. (2010). An analysis tool for design and certification of postbuckling composite aerospace structures. International Journal of Structural Stability and Dynamics, 10(4), 669-681. https://doi.org/10.1142/S0219455410003671

Document Version: Accepted Manuscript

Published Version: https://doi.org/10.1142/S0219455410003671

Repository homepage: https://researchrepository.rmit.edu.au

(C) 2010 World Scientific Publishing Company

Downloaded On 2023/04/26 23:39:57 +1000 
Thank you for downloading this document from the RMIT Research Repository.

The RMIT Research Repository is an open access database showcasing the research outputs of RMIT University researchers.

RMIT Research Repository: http://researchbank.rmit.edu.au/

\section{Citation:}

Orifici, A, Thomson, R, Degenhardt, R, Bisagni, C and Bayandor, J 2010, 'An analysis tool for design and certification of postbuckling composite aerospace structures', International Journal of Structural Stability and Dynamics, vol. 10, no. 4, pp. 669-681.

See this record in the RMIT Research Repository at:

http://researchbank.rmit.edu.au/view/rmit:8877

Version: Accepted Manuscript

Copyright Statement: (c) 2010 World Scientific Publishing Company

Link to Published Version:

http://dx.doi.org/10.1142/S0219455410003671 


\title{
AN ANALYSIS TOOL FOR DESIGN AND CERTIFICATION OF POSTBUCKLING COMPOSITE AEROSPACE STRUCTURES
}

\author{
ADRIAN C. ORIFICI ${ }^{1}$ \\ School of Aerospace, Mechanical and Manufacturing Engineering, Royal Melbourne Institute of Technology \\ GPO Box 2476V, Melbourne, Victoria 3001, Australia \\ adrian.orifici@rmit.edu.au \\ RODNEY S. THOMSON \\ Cooperative Research Centre for Advanced Composite Structures \\ 506 Lorimer Street, Fishermans Bend, Victoria 3207, Australia \\ r.thomson@crc-acs.com.au \\ RICHARD DEGENHARDT \\ Institute of Composite Structures and Adaptive Systems, DLR - German Aerospace Center \\ Lilienthalplatz 7, 38108 Braunschweig, Germany \\ richard.degenhardt@dlr.de \\ CHIARA BISAGNI \\ Dipartimento di Ingegneria Aerospaziale, Politecnico di Milano, \\ Via La Masa 34, 20156 Milan, Italy \\ chiara.bisagni@polimi.it \\ JAVID BAYANDOR \\ The Sir Lawrence Wackett Aerospace Centre \\ School of Aerospace, Mechanical and Manufacturing Engineering, Royal Melbourne Institute of Technology \\ GPO Box 2476V, Melbourne, Victoria 3001, Australia \\ javid.bavandor@rmit.edu.au \\ Received (Day Month Year) \\ Accepted (Day Month Year)
}

In aerospace, carbon fibre-reinforced polymer (CFRP) composites and postbuckling skin-stiffened structures are key technologies that have been used to improve structural efficiency. However, the application of composite postbuckling structures in aircraft has been limited due to concerns related to both the durability of composite structures and the accuracy of design tools. In this work, a finite element analysis tool for design and certification of aerospace structures is presented, which predicts collapse by taking the critical damage mechanisms into account. The tool incorporates a global-local analysis technique for predicting interlaminar damage initiation, and degradation models to capture

\footnotetext{
${ }^{1} 506$ Lorimer Street, Fishermans Bend, Victoria 3207, Australia.
} 
the growth of a pre-existing interlaminar damage region, such as a delamination or skin-stiffener debond, and in-plane ply damage mechanisms such as fibre fracture and matrix cracking. The analysis tool has been applied to single- and multi-stiffener fuselage-representative composite panels, in both intact and pre-damaged configurations. This has been performed in a design context, in which panel configurations are selected based on their suitability for experimental testing, and in an analysis context for comparison with experimental results as representative of aircraft certification studies. For all cases, the tool was capable of accurately capturing the key damage mechanisms contributing to final structural collapse, and suitable for the design of next-generation composite aerospace structures.

Keywords: COCOMAT, stiffened structures, postbuckling, interlaminar damage, ply damage

\section{Introduction}

Carbon fibre-reinforced polymer composites are being increasingly used in aerospace and many other industries due to their high performance and lightweight properties. This can be seen in the increasing use of composite materials for aircraft primary structures, which typically involve thin skins reinforced periodically by stiffeners. Under compression, composite aerospace structures develop a range of buckling and damage modes that combine to cause structural collapse ${ }^{1-3}$. Despite a considerable amount of research into damage models and analysis tools, particularly in recent years ${ }^{4-6}$, the aerospace industry is still heavily reliant on experimental testing for design and analysis of composite structures. This is due in part to the difficulty in accurately capturing all of the key damage mechanisms contributing to collapse. This difficulty in turns leads to a significant degree of conservatism in current aerospace composite structure design.

In this work, a finite element (FE) analysis tool was developed for predicting the collapse of stiffened composite structures in compression that focuses on capturing the effects of the critical damage mechanisms. The tool contains several aspects: predicting initiation of interlaminar damage in intact structures; capturing in-plane degradation; and, capturing the propagation of a pre-existing interlaminar damage region. The analysis tool was implemented into MSC.Marc v2005r3 (Marc) ${ }^{7}$ by a combination of user subroutines, and supported by utilities for pre- and post-processing within a user-friendly menu system developed in MSC.Patran (Patran). ${ }^{7,8}$ The tool and various damage and degradation models were extensively validated using experimental results at a range of different length scales. This work was conducted as part of the European Commission Project COCOMAT, which focused on exploiting the large strength reserves of composite aerospace structures through a more accurate prediction of collapse. ${ }^{9}$ 


\section{Analysis Tool}

The developed tool contains several aspects: predicting initiation of interlaminar damage in intact structures; capturing in-plane degradation; and, capturing the propagation of a pre-existing interlaminar damage region. These aspects are described in the subsequent sections. This is followed by a description of the user interface created in Patran for preand post-processing.

\subsection{Interlaminar damage initiation}

The approach for predicting the initiation of interlaminar damage in the skin-stiffener interface was based on a global-local technique and has been presented previously. ${ }^{10,11}$ In this technique, a global shell model of the full structure was used to determine the deformation field of the entire structure, which was then input as boundary conditions on a local three-dimensional (3D) brick model of a skin-stiffener interface. In the local model the strength-based "degenerated Tsai" criterion (2.1) was used, as given by

$$
\left(\sigma_{\mathrm{x}} / X_{\mathrm{T}}\right)^{2}+\left(\sigma_{\mathrm{z}} / Z_{\mathrm{T}}\right)^{2}+\left(\tau_{\mathrm{yz}} / S_{\mathrm{yz}}\right)^{2} \geq 1 .
$$

This criterion was monitored in order to predict the initiation of delamination or skinstiffener separation, and was applied to elements defining the plies. Failure was deemed to occur when the average of all integration point values in an element satisfied this criterion. By modifying the location of the 3D local model, the initiation of interlaminar damage throughout the panel could be investigated in order to determine the most critical skin-stiffener interface location. The prediction of delamination in local skin-stiffener interfaces using this approach has been successfully demonstrated previously. ${ }^{12,13}$ This involved skin-stiffener panels of various geometries and construction methods cut into thin strips, and loaded to simulate the symmetric and antisymmetric deformations associated with postbuckling. The analysis approach for these specimens was able to give accurate predictions of failure load and location within the experimental scatter, and was used to determine the sensitivity of the specimen to various experimental parameters.

\subsection{Ply damage}

For the ply damage degradation model ${ }^{11,14}$, an approach based on the Hashin ${ }^{15}$ failure criteria and stiffness reduction method of Chang and Lessard ${ }^{16}$ was used. The criteria for fibre failure, matrix cracking and fibre-matrix shear failure were monitored and used to reduce the appropriate material properties to zero upon detection of failure. This approach is summarised in Table 1, which lists the failure modes monitored, the criteria used, and the ply properties reduced upon detection of failure. 
Table 1: In-plane failure criteria and property reduction

\begin{tabular}{|c|c|c|}
\hline Failure type & Criterion & Properties reduced \\
\hline $\begin{array}{l}\text { Fibre, tension } \\
\text { Fibre, compression }\end{array}$ & $\begin{array}{l}\left(\sigma_{11}^{2} / X_{T}^{2}\right)^{\frac{1}{2}} \geq 1 \\
\left(\sigma_{11}^{2} / X_{C}^{2}\right)^{\frac{1}{2}} \geq 1\end{array}$ & $\begin{array}{c}E_{11}, E_{22} \\
G_{12}, G_{23}, G_{31}\end{array}$ \\
\hline Matrix, tension & $\left(\sigma_{22}^{2} / Y_{T}^{2}+\tau_{12}^{2} / S_{12}^{2}\right)^{\frac{1}{2}} \geq 1$ & \\
\hline Matrix, compression & $\left(\frac{\sigma_{22}}{Y_{C}}\left(\frac{Y_{C}^{2}}{4 S_{23}^{2}}-1\right)+\frac{\sigma_{22}^{2}}{4 S_{23}^{2}}+\frac{\sigma_{12}^{2}}{4 S_{12}^{2}}\right)^{\frac{1}{2}} \geq 1$ & $E_{22}$ \\
\hline $\begin{array}{l}\text { Fibre-matrix shear, tension } \\
\text { Fibre-matrix shear, } \\
\text { compression }\end{array}$ & $\begin{array}{c}\left(\sigma_{12}^{2} / S_{12}^{2}\right)^{\frac{1}{2}} \geq 1 \\
\left(\sigma_{11}^{2} / X_{C}^{2}+\sigma_{12}^{2} / S_{12}^{2}\right)^{\frac{1}{2}} \geq 1\end{array}$ & $G_{12}, G_{31}$ \\
\hline
\end{tabular}

\subsection{Interlaminar damage growth}

In the interlaminar damage growth model, pre-existing damage in the skin-stiffener interface was represented as a debonded region between the skin and stiffener. ${ }^{18,19}$ Nominally coincident shell layers were connected with user-defined multi-point constraints (MPCs), as illustrated in Fig. 1. The user-defined MPCs were given one of three states to define the intact (state 0), crack front (state 1) and debonded (state 2) regions. Gap elements were used in any debonded region to prevent crossover of the two sublaminates. At the end of every nonlinear analysis increment, the Virtual Crack Closure Technique (VCCT) was used to determine the strain energy release rates of all MPCs on the crack front. For crack propagation, the B-K mixed-mode failure criterion ${ }^{17}$ was applied, as given by

$$
\frac{\left(G_{I}+G_{I I}+G_{I I I}\right)}{\left(G_{I C}+\left(G_{I I C}-G_{I C}\right)\left[\left(G_{I I}+G_{I I I}\right) /\left(G_{I}+G_{I I}+G_{I I I}\right)\right]^{\eta}\right)}=1,
$$

where $G$ are the strain energy release rates in modes I, II and III, $G_{C}$ are fracture toughness values, and $\eta$ is a curve fit parameter found from mixed-mode test data. The $\mathrm{B}-\mathrm{K}$ criterion was applied in an iterative method that was based on reducing the estimated energy release rate based on the shape of the crack front in propagation. The iterative approach was developed as it was found that a simple fail-release method led to violation of the assumption of self-similar growth. ${ }^{18,19}$ The prediction of interlaminar crack growth was validated using fracture mechanics characterisation specimens, including mode I double cantilever beam (DCB), ${ }^{18}$ mode II end notched flexure, ${ }^{19}$ mode III edge crack torsion, ${ }^{8}$ and mode I-II mixed-mode bending (MMB). ${ }^{19}$ From these specimens, the crack growth degradation model with the iterative propagation method was shown to be capable of accurately representing specimen behaviour under single and mixed-mode crack growth. Further information on this approach is also presented in Refs 11 and 14. 


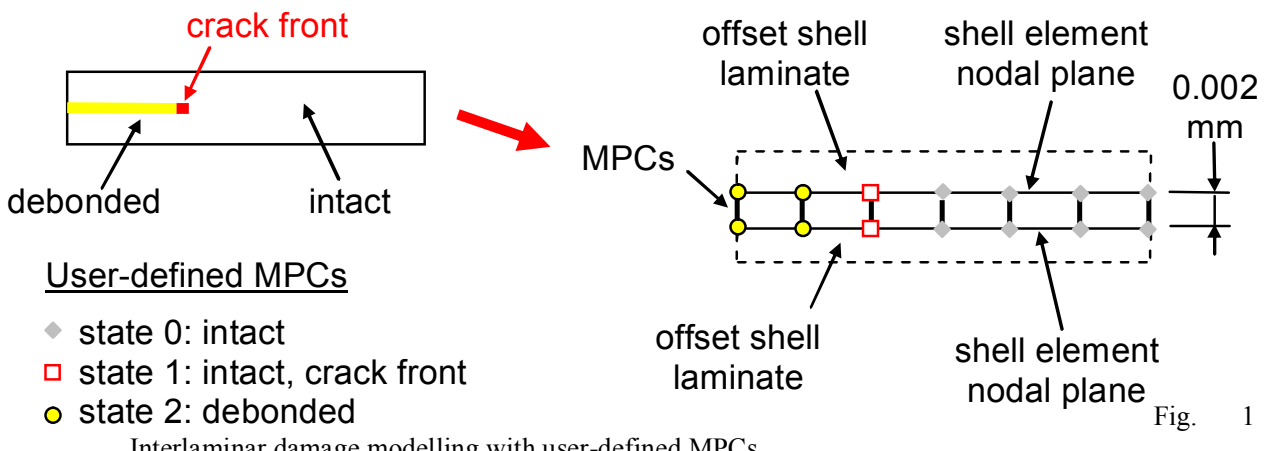

\subsection{User Interface}

The damage and degradation models were incorporated as a user-friendly package for the collapse analysis of composite structures taking degradation into account. As part of this, there were a range of capabilities that were necessary for the tool to be applicable across different analysis scenarios. The most obvious scenario was the analysis of intact or predamaged postbuckling designs, which was commonly used as pre- and post-test simulations of experimental results. Another important scenario was in the design of postbuckling structures, where parametric investigations were performed to select specimen configurations favourable for either experimental investigation or real world application. For both of these scenarios, it was necessary that the tool was easy to use, required minimal knowledge of the degradation models, and provided the functionality to investigate the various composite damage mechanisms in postbuckling structures.

The analysis tool was implemented as a menu system within Patran, and was intended to act as a complement to the model definition and analysis functions in Patran. In this way, the user would first define the mesh, boundary condition, material, property and load case data for the model using the standard Patran functions. Separate sub-menus (and associated help menus) were then developed for a range of actions, including defining the damage regions and properties, running the analysis, and assisting in the post-processing of the results. An example of a sub-menu is given in Fig. 2, which shows the actions available for defining the damage, and an example model file with damage defined.

\section{Design and Analysis}

The analysis tool has been applied to the design and analysis of fuselage-representative composite panels, which are summarised in Fig. 3. Different panel designs were considered, which corresponded to COCOMAT Design 1 (D1), Design 2 (D2) and Design 6 (D6) configurations. Single-stiffener flat panels and multi-stiffener curved panels were considered in both undamaged and pre-damaged configurations. Pre-damage 
was introduced using Teflon inserts to generate a skin-stiffener debond, and with impact to generate barely visible impact damage (BVID).
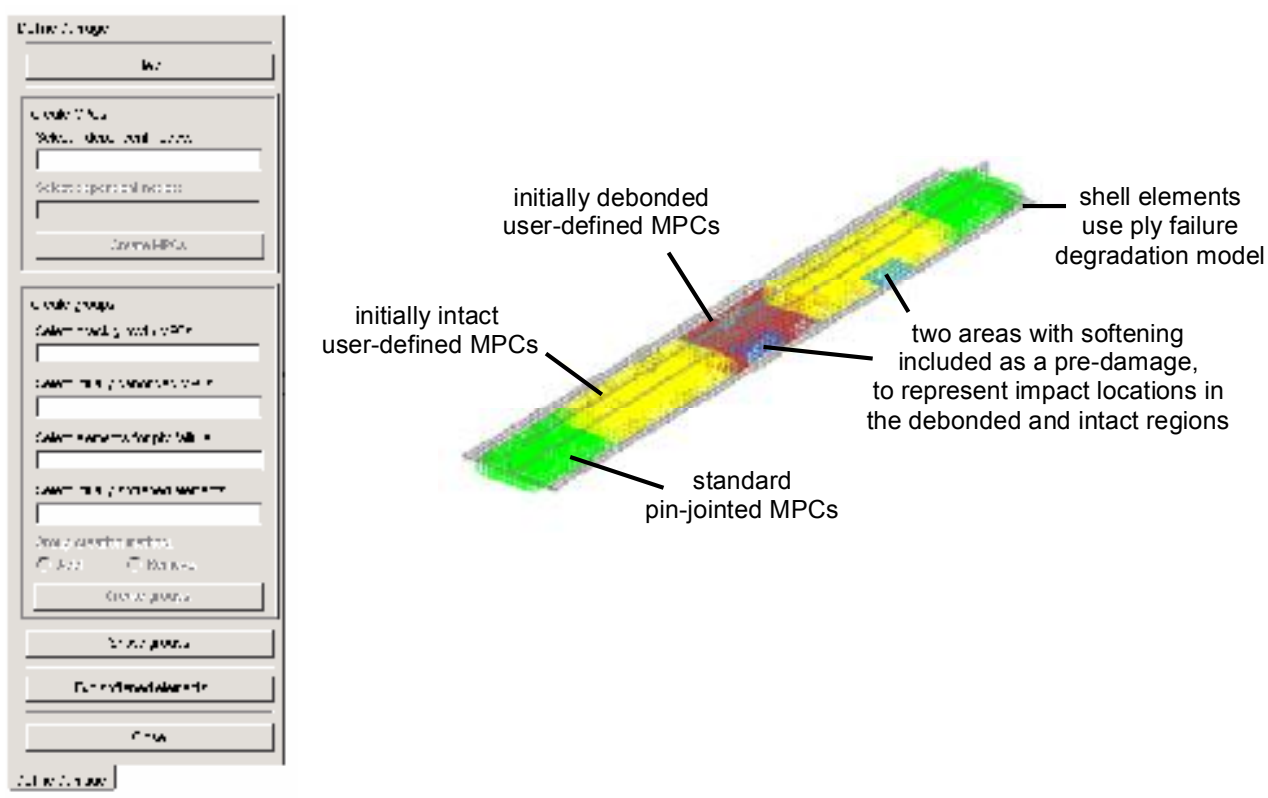

Fig. 2 Left: The Define Damage sub-menu. Right: Example model (single-stiffener specimen) showing damage definition

\section{Single-stiffener flat panels}

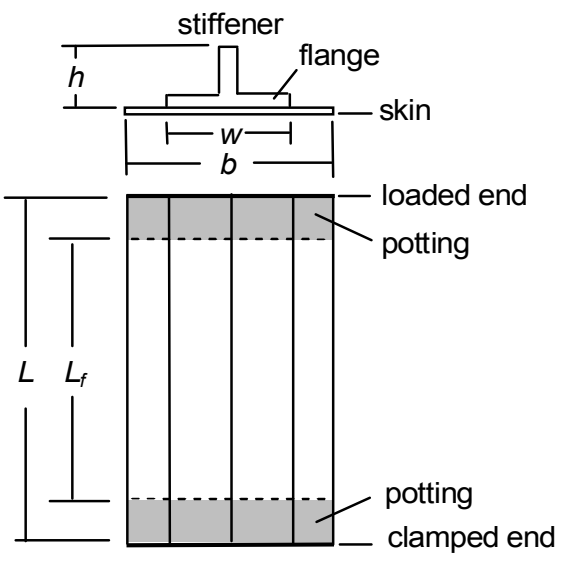

Multi-stiffener curved panels

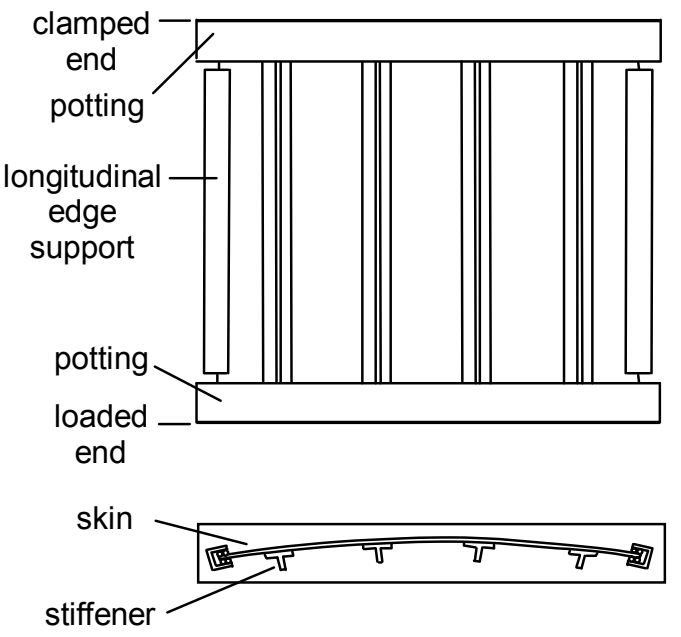

Fig. 3 Fuselage-representative stiffened panel designs 


\subsection{Design studies}

For panel design, intact configurations were selected based on COCOMAT partners' previous experience, and the analysis tool was applied to investigate pre-damaged configurations suitable for experimental testing. As such, the design process was conducted from a research-based perspective, so that designs were recommended based on being suitable for validation of analysis tools. In this respect, initiation of damage early in the postbuckling region, a stable postbuckling mode shape, and steady and observable damage progression were all key criteria for design selection.

For the D2 panel, pre-damage was implemented using BVID, which corresponds to an impact indentation depth of $1 \mathrm{~mm}$. Based on industrial experience, it was decided to impact the panel at two locations of maximum compression strain, with the impact onto the skin in the region of the stiffener flange. From analysis of an undamaged panel in postbuckling, maximum strain in the skin and stiffener occurred along anti-nodal and nodal lines respectively (locations of maximum and minimum displacement as seen in Fig. 4). Previous experience from FE analysis and experimental studies was used to characterise the extent of damage through the laminate due to BVID, and various impact models were analysed as shown in Fig. 4. The impact models corresponded to different combinations of fibre fracture, matrix cracking and a skin-stiffener debond in order to represent the impact locations. These models used 6,032 four-node shell elements and 1,908 user-defined MPCs.

As shown in Fig. 5, it was found that for all impact models nodal locations gave slightly higher damage propagation, which was more pronounced for more severe impact representations. This is because the stiffeners provide the dominant contribution to panel behaviour. As such, nodal impact locations were recommended for experimental investigation, as the increased damage was more suitable with respect to validation of analysis tools.
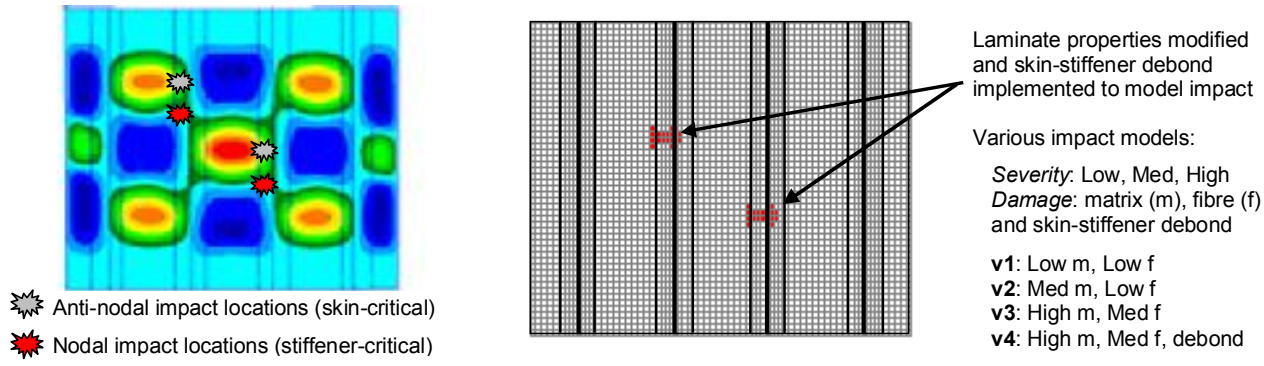

Fig. 4 Left: D2 panel (no damage), out-of-plane deformation in postbuckling, with nodal and anti-nodal impact locations shown. Right: FE mesh (stiffeners outlined), showing elements selected for representing impact location (nodal impact locations shown). 

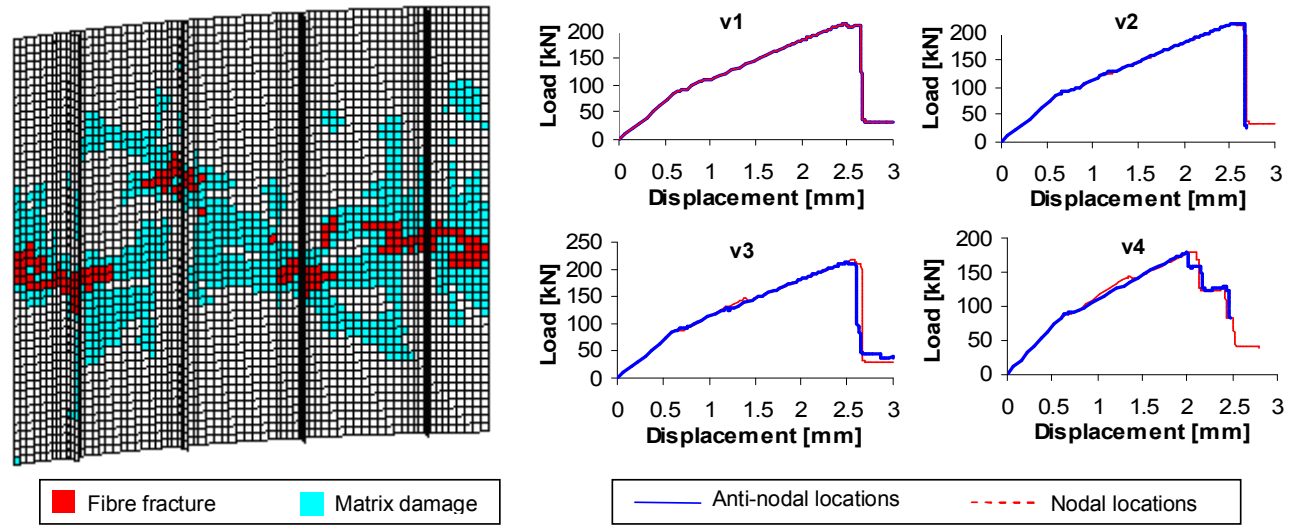

Fig. 5 Left: In-plane damage at $3.0 \mathrm{~mm}$ axial displacement, nodal v4 impact model (debond growth not shown). Right: Applied load-displacement curve for node and anti-node models, with different impact representations (v1-v4).

In other analyses for D1 and D6 panels, pre-damaged configurations were investigated using Teflon-generated skin-stiffener debonds. This was achieved with the interlaminar damage propagation approach by modifying the properties of the user-defined MPCs to model skin-stiffener debonds. The design studies for these panels have been presented in previous publications. ${ }^{20,21}$ For the D1 panel, ${ }^{20}$ a single full-width debond per panel was implemented, and the parameters investigated were the debond length, the choice of stiffener, and the location of the debond underneath a stiffener. For the D6 panel, ${ }^{21}$ three debonds under different stiffeners were implemented, and the parameters investigated were the debond length, location and the width of the debond across the stiffener flange.

\subsection{Comparison with experiment}

The analysis tool has also been extensively applied to provide numerical predictions in comparison with experimental results, which is representative of the analysis process for aircraft certification. This has been performed for single-stiffener and multi-stiffener panels, in both intact and pre-damaged (Teflon debonds) configurations. The manufacture and testing for all panels was conducted within the COCOMAT project. The panels for which analysis has been performed were shown in Fig. 3 and are listed below, where in all cases the experimental and numerical results have been previously published.

- $\quad$ Single-stiffener flat panels corresponding to D1 and D2 designs in both intact and pre-damaged configurations manufactured and tested by Aernnova Engineering Solutions (Aernnova). ${ }^{14}$

- An intact and pre-damaged multi-stiffener curved D6 panel, both manufactured by Israel Aerospace Industries and tested by Technion - Israel Institute of Technology. ${ }^{21}$ 
- A multi-stiffener curved D2 panel manufactured at Aernnova and tested at the Institute of Composite Structures and Adaptive Systems at German Aerospace Center (DLR). ${ }^{11}$

- Two pre-damaged multi-stiffener D1 panels manufactured at Aernnova and tested at DLR, the first in which skin-stiffener debonds were introduced using cyclic loading into the postbuckling region, ${ }^{11}$ and another that used Teflongenerated skin-stiffener debonds. ${ }^{20}$

A summary of all comparison with experimental results is given in Fig. 6. The mesh density for these panels was similar to that shown for the D2 panel in Section 3.1, where depending on the dimensions element sizes of around $5-10 \mathrm{~mm}$ and total element numbers of around 6,000 to 9,000 were common. It should be noted that for the D1 predamaged panel P36 (the top right image), the numerical predictions did not include ply damage and so did not capture collapse. Similarly, for the D6 pre-damaged panel VER I (the bottom right graph), the experimental panel was not taken to collapse. Overall, it is clear from Fig. 6 that the analysis tool predictions compared very well with the experimental results, in terms of the load response, ultimate load and damage behaviour. In general, the comparison with all experimental results demonstrated that the analysis tool allowed for in-depth analysis of the critical damage mechanisms, and was able to illustrate the way in which these mechanisms combined to produce final panel collapse.

\section{Discussion}

There are a number of factors that were seen to influence the applicability and predictive capability of the analysis tool. One aspect was the difficulty in accurately capturing the correct buckling mode shapes and deformation patterns, which was especially critical for crack opening displacements just ahead of any crack front. This is related to the presence of imperfections in the experimental panels, both in geometry and in boundary conditions, which are critical for any buckling analysis. Furthermore, the computational time was quite high, with analyses involving crack growth and fibre fracture taking several days to complete on a single processor CPU. Although no direct comparison with other analysis tools was made, accurate analysis of damage mechanisms in general is always going to be computationally expensive given the complexity and high degree of nonlinearity.

In this work, the strength and fracture toughness parameters were taken or assumed from material characterisation test data, and were not adjusted either in comparison with experimental results or to assist with numerical computation. However, the application of accurate and representative material properties is a key issue for all damage models. This is particularly true for interlaminar damage, where fracture mechanics values are based on simplifying assumptions and involve a considerable degree of variability even in 
simple characterisation tests. More discussion on these aspects for strength and fracture mechanics predictions is given in other references. ${ }^{13,14}$

The influence of mesh density remains significant for any analysis, particularly with respect to strength-based failure predictions and crack growth analysis. For the interlaminar damage progression model, extensive mesh sensitivity studies were conducted for fracture mechanics characterisation specimens, with limited mesh sensitivity found. ${ }^{8,18,19}$ The ply damage degradation model is likely to be dependent on the mesh to some extent, particularly at stress concentrations, given the knockdown approach to softening. Though no serious mesh sensitivity effects were noted in this work, this effect can be mostly alleviated through the integration of the element length with an energy-based softening, as discussed in Ref. 6. Similarly, the application of the interlaminar damage initiation at stress concentrations requires careful consideration of the mesh size, and in this work the mesh size was calibrated as discussed in other references. ${ }^{12,13}$ For all damage models, the mesh size was not seen to be a limiting factor for either the accuracy or computational expense, and it was not found to be necessary to modify any of the material properties based on the mesh size.

The analysis tool has application for exploiting the strength reserve of postbuckling composite aerospace structures in both design and certification scenarios. The interlaminar and ply damage models are recommended to be included wherever the effects of these damage mechanisms are considered necessary to be captured. For example, with design studies it may be suitable to predict initiation of damage only instead of damage progression, whilst damage tolerance studies would require damage progression to be captured. Through advanced analysis procedures and an understanding of the way in which the damage mechanisms develop, interact and contribute to collapse, the load-carrying capability of a composite structure can be more reliably predicted. This will allow the onset of composite damage mechanisms to occur within the safe operating region of the aircraft flight loads, which is currently not permitted. In this way, the high level of conservatism associated with damage can be reduced for the next generation of composite aerospace structures. 

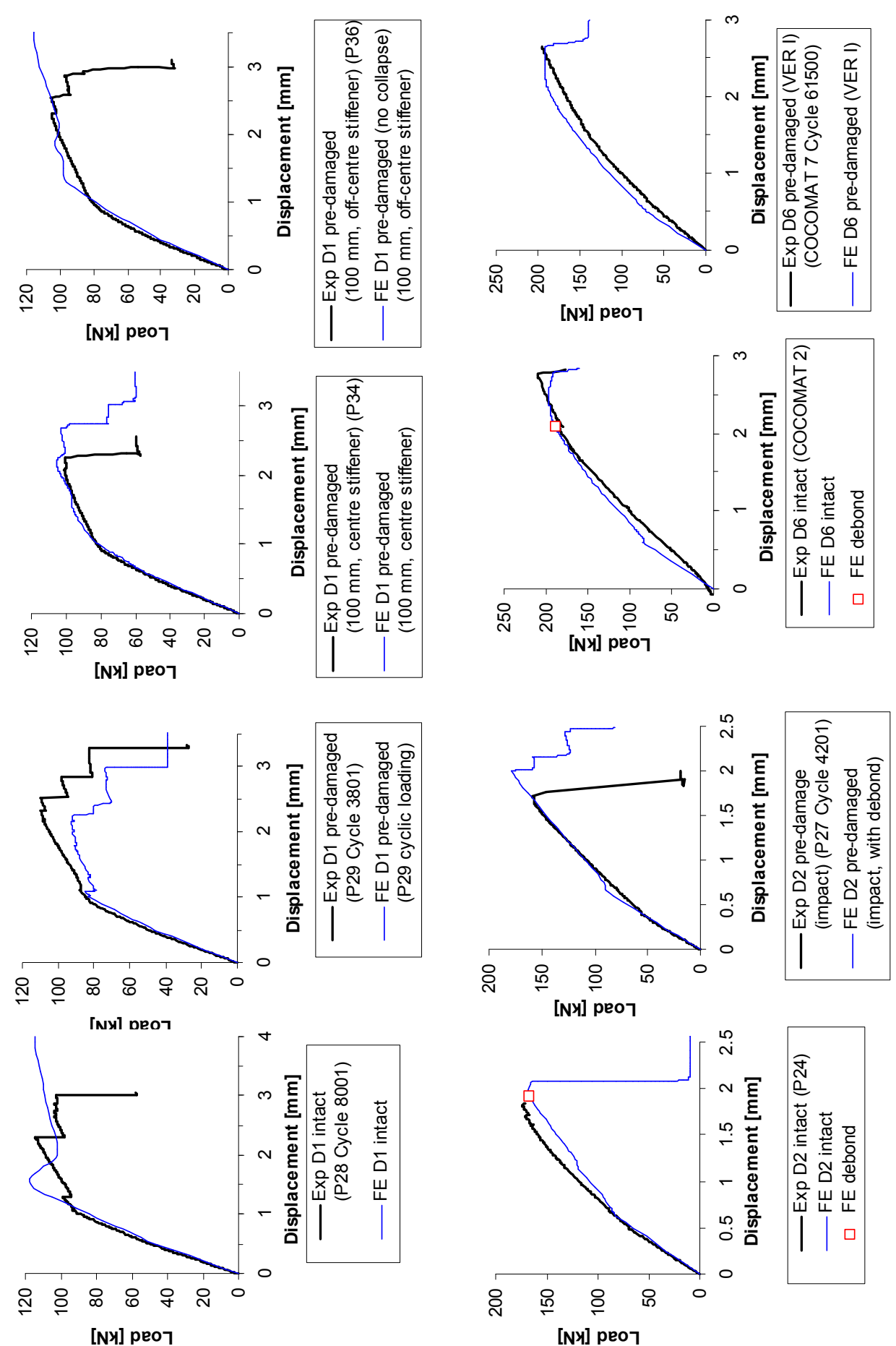

Fig. 6 Comparison betw een experimental results and analysis tool predictions 


\section{Conclusion}

An analysis tool has been developed for predicting the collapse of postbuckling composite aerospace structures. A feature of this tool is the incorporation of various degradation models to capture the key composite damage mechanisms. This includes a strength-based global-local approach for predicting interlaminar damage initiation, a strength-based ply progressive failure approach based on the work of Hashin ${ }^{15}$ and Chang and Lessard, ${ }^{16}$ and an interlaminar damage growth model that uses MPCs controlled by the VCCT. These damage models were incorporated into the Patran software program via a set of user-friendly sub-menus providing a range of pre-and post-processing functions. The analysis tool was validated extensively using experimental results at a range of different length scales, and its application was demonstrated for the design and certification of postbuckling composite aerospace structures.

\section{Acknowledgments}

This research is part of the Research Program of the Cooperative Research Centre for Advanced Composite Structures (CRC-ACS) Ltd. The authors kindly acknowledge the financial support of: the Australian Postgraduate Awards Scheme; CRC-ACS; the German Academic Exchange Service (DAAD), the Italian Ministry of Foreign Affairs, and; the Australian Government under both the "Innovation Access Programme International Science and Technology" and "International Science Linkages" established under the Australian Government's innovation statement, "Backing Australia's Ability". The work of the experimental testing staff at the Institute of Composite Structures and Adaptive Systems at DLR Braunschweig, the Technion Aerospace Structures Laboratory, Aernnova and RWTH Aachen is also gratefully acknowledged. COCOMAT is supported by the European Commission, Priority Aeronautics and Space, Contract AST3-CT-2003502723 .

\section{References}

1. R. Zimmermann, H. Klein and A. Kling, Buckling and postbuckling of stringer stiffened fibre composite curved panels - tests and computations. Composite Structures, 73 (2006) 150-161.

2. E. S. Greenhalgh, C. Meeks, A. Clarke and J. Thatcher, The effect of defects on the performance of post-buckled CFRP stringer-stiffened panels. Composites: Part A, 34 (2003) 623-633.

3. E. Gal, R. Levy, H. Abramovich and P. Pavsner, Buckling analysis of composite panels. Composite Structures, 73 (2006) 179-185. 
4. M.J. Hinton, A.S. Kaddour and P.D. Soden, Failure Criteria in Fibre-ReinforcedPolymer Composites, Elsevier, The Netherlands, (2004).

5. P.P. Camanho, C.G. Dávila, S.T. Pinho, L. Iannucci and P. Robinson, Prediction of in situ strengths and matrix cracking in composites under transverse tension and inplane shear. Composites Part A, 37 (2006) 165-176.

6. I. Lapczyk. and J.A. Hurtado, Progressive damage modelling in fiber-reinforced materials. Composites - Part A, 38 (2007) 2333-41.

7. MSC.Software Corporation, Santa Ana, California.

8. A. C. Orifici, Degradation Models for the Collapse Analysis of Composite Aerospace Structures. PhD thesis, Royal Melbourne Institute of Technology, (2007).

9. R. Degenhardt, R. Rolfes, R. Zimmermann and K. Rohwer, COCOMAT - Improved MATerial Exploitation at Safe Design of COmposite Airframe Structures by Accurate Simulation of COllapse, Composite Structures, 73 (2006) 175-178.

10. A. C. Orifici, R. S. Thomson, I. Herszberg, T. Weller, R. Degenhardt and J. Bayandor, An analysis methodology for failure in postbuckling skin-stiffener interfaces, Composite Structures, 86 (2008) 186-193.

11. A. C. Orifici, R. S. Thomson, R. Degenhardt, C. Bisagni and J. Bayandor, A finite element methodology for analysing degradation and collapse in postbuckling composite aerospace structures. Journal of Composite Materials, (accepted).

12. A. C. Orifici, I. Herszberg, R. S. Thomson, T. Weller, A. Kotler, and J. Bayandor, Failure in stringer interfaces in postbuckled composite stiffened panels. 12th Australian International Aerospace Congress, Melbourne, Australia, 19-22 March 2007.

13. A. C Orifici, S. A. Shah, I. Herszberg, A. Kotler, T. Weller, Failure analysis in postbuckled composite T-sections, Composite Structures, 86 (2008) 146-153.

14. A. C. Orifici, I. Ortiz de Zarate Alberdi, R. S. Thomson, J. Bayandor, Compression and post-buckling damage growth and collapse analysis of flat composite stiffened panels, Composites Science and Technology, 68 (2008) 3150-3160.

15. Z. Hashin, Failure criteria for unidirectional composites. Journal of Applied Mechanics, 47 (1980) 329-334.

16. F. K. Chang and L. B. Lessard, Damage tolerance of laminated composites containing an open hole and subject to compressive loadings: part I - analysis. Journal of Composite Materials, 25 (1991) 2-43.

17. M.L. Benzeggagh and M. Kenane, Measurement of mixed-mode delamination fracture toughness of unidirectional glass/epoxy composites with mixed-mode bending apparatus. Composites Science and Technology, 56 (1996) 439-449.

18. A. C. Orifici, R. S. Thomson, R. Degenhardt, C. Bisagni and J. Bayandor, Development of a finite element methodology for the propagation of delaminations in composite structures. Mechanics of Composite Materials, 43(1) (2007) 9-28.

19. A. C. Orifici, R. S. Thomson, R. Degenhardt, S. Büsing and J. Bayandor, Development of a finite element methodology for modelling mixed-mode 
delamination growth in composite structures. 12th Australian International Aerospace Congress, Melbourne, Australia, 19-22 March 2007.

20. A. C. Orifici, R. S. Thomson, R. Degenhardt and J. Bayandor, The use of damage as a design parameter for postbuckling composite aerospace structures, in 26th Congress of International Council of the Aeronautical Sciences (ICAS 2008), Anchorage, USA, 14-19 September 2008.

21. A. C. Orifici, S. Lauterbach, H. Abramovich, R. S. Thomson, W. Wagner, C. Balzani, Analysis of damage sensitivity and collapse in postbuckling fibrereinforced multi-stiffener panels, 2nd International Conference on Buckling and Postbuckling Behaviour of Composite Laminated Shell Structures, Braunschweig, Germany, 3-5 September 2008. 